\title{
Initial clinical experience of two UK centres with ex vivo normothermic perfusion (EVNP) of deceased donor kidneys
}

\author{
Pankaj Chandak ${ }^{1}$, Avinash Sewpaul ${ }^{2}$, Benedict Phillips' ${ }^{1}$, Rodrigo Figueiredo ${ }^{2}$, Lucy Bates ${ }^{2}$, \\ Raphael Uwechue $^{1}$, Colin Wilson ${ }^{2}$, Chris Callaghan', Sarah Hosgood ${ }^{3}$, Mike Nicholson ${ }^{3}$. \\ ${ }^{1}$ Guy's Hospital London; ${ }^{2}$ Freeman Hospital, Newcastle; ${ }^{3}$ Addenbrooke's Hospital, Cambridge
}

\section{Introduction}

Kidney EVNP may reduce delayed graft function (DGF) and can also be used to assess organ viability in marginal organs at high risk of discard. Thus far, its use has been pioneered by a single UK group. If EVNP is to fulfil its early promise it is essential that the technique is translatable to other centres. We describe the first clinical experience of kidney EVNP outside of the Cambridge group.

\section{Methods}

EVNP was authorised as a new procedure at Guy's Hospital and the Freeman Hospital. Formal EVNP training programmes took place with the Cambridge group, with proformas used to assess competencies. EVNP of discarded deceased donor kidneys $(n=5)$ was used in each unit to demonstrate technical proficiency before clinical EVNP programmes began in March 2016 (Freeman) and July 2016 (Guy's). Kidneys from extended criteria donors, DCD donors, or those with suboptimal cold flush underwent 60 minutes of EVNP at a target pressure of $75 \mathrm{mmHg}$. Viability was assessed using a validated scoring system ( 1 best -5 worst). Significant adverse technical events during EVNP were prospectively recorded, as were post-transplant outcomes.

\section{Results}

Sixteen kidneys from 14 deceased donors (DCD $n=15$, DBD $n=1$ ) underwent EVNP at the two new centres (Figure 1). Median (range) donor age was 66 (17-72) years. One kidney had transient arterial decannulation at Guy's; no other significant adverse technical events occurred during EVNP. Cannula fixation techniques have been modified at Guy's and no further decannulation events have occurred. Median (range) kidney viability score was 1 (1-4). Two kidneys were not transplanted after assessment on EVNP; the first kidney scored 4 on EVNP and was therefore deemed untransplantable, the second kidney scored 3, and was deemed unsuitable for the intended recipient. In total, 14 organs were implanted into 12 recipients. Two dual kidney transplants after EVNP were performed at Guy's Hospital.
Median (range) recipient age was 60.5 (28-64) years, and mean time from donor cross-clamp to recipient reperfusion was $16 \mathrm{hr} 56(09 \mathrm{hr} 26-24 \mathrm{hr} 00)$. Six recipients $(50 \%)$ had DGF, and median (range) one-month eGFR was $49.5(13-62.6) \mathrm{mL} / \mathrm{min} / 1.73 \mathrm{~m}^{2}$. Graft and patient survival is $100 \%$. No major infectious complications occurred post-transplant in EVNP kidney recipients.

Figure I - Flow diagram of EVNP enrolment and outcome

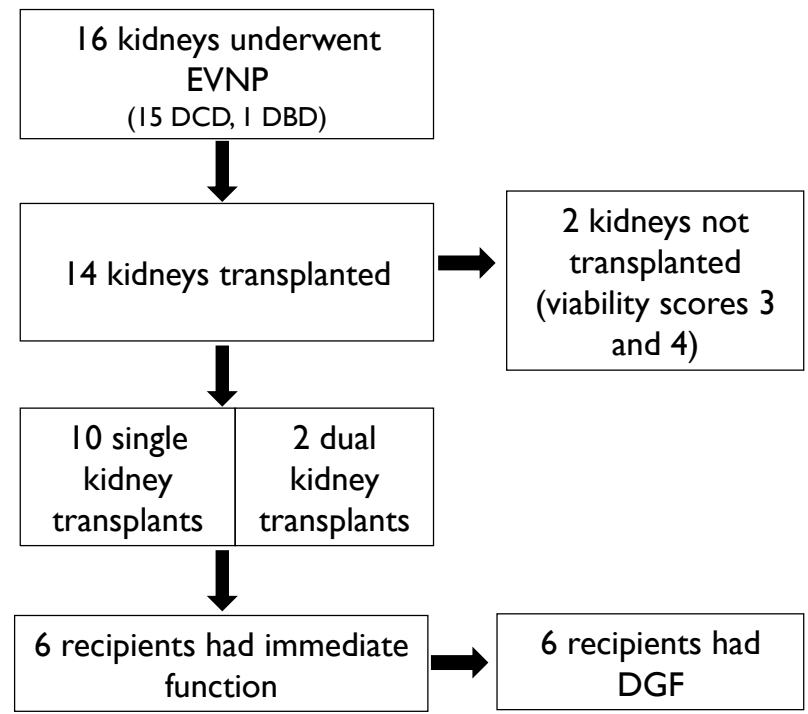

\section{Discussion}

Two UK units have initiated clinical EVNP programmes in deceased donor kidney transplantation, with acceptable early outcomes. The first use of EVNP prior to dual kidney transplantation is described. Rapid transfer of EVNP skills is feasible with a supervising centre providing a training programme, support, and mentorship. An RCT is underway to provide further evidence on the utility of EVNP to reduce DGF in DCD kidneys.

\section{Funding}

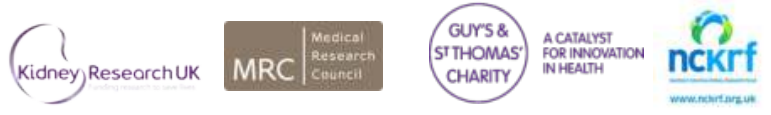

